Available Online at https://journal.unismuh.ac.id/index.php/otoritas

Otoritas : Jurnal Ilmu Pemerintahan, 11 (1), April 2021, 33-44

\title{
The Life Changer: Social Workers in Rehabilitation Facilities for Child in Conflict with the Law
}

\author{
Mark Erana Patalinghug1*) \\ ${ }^{1}$ Department of Criminology, Faculty of Bachelor of Science in Criminology, J.H. Cerilles State College- \\ Dumingag Campus, Caridad, Dumingag Zamboanga del Sur, 7028, Mindanao Philippines.
}

Received: 29 March 2021; Revised: 20 April 2021; Accepted: 30 April 2021

\begin{abstract}
Delinquent minors are offered special services intended to prevent them from entering the juvenile justice system. Through productive activities, delinquents are trained to acquire socially acceptable behavior with the help of social workers. This phenomenological study explored the social workers' experiences in handling juvenile cases. The study focused on 10 social workers from rehabilitation facilities of children in conflict with the law in the Zamboanga Peninsula Region, Philippines. The result of the study revealed that working with the juvenile's case, social workers have encountered positive and negative experiences. The study leads to the challenges and plight of social workers in their day-to-day activity in juvenile case management. As for how the participants coped with the challenges, they have been mentored and adjusted very well like their work. They also managed their challenges by viewing them as advocacy and service to humanity through altruistic activities.
\end{abstract}

Keywords: Juvenile Rehabilitation; Challenges of Social Workers; Role of Social workers

How to Cite: Patalinghug, M.E. (2021). The Life Changer: Social Workers in Rehabilitation Facilities for Child in Conflict with the Law. Otoritas : Jurnal Ilmu Pemerintahan, 11(1), 3344.

Permalink/DOI: https://doi.org/10.26618/ojip.v11i1.5072

${ }^{*}$ Corresponding Author.

E-Mail : mark.patalinghug@jhcsc.edu.ph

Copyright (C) 2021, Otoritas : Jurnal Ilmu Pemerintahan, ISSN: 2088-3706 (Print), ISSN: 2502-9320 (Online) 


\section{INTRODUCTION}

As a profession, social work highlights the growth of social workers' personal qualities, and also needs them to possess the professional values, experience, theories, and practical skills are required (Kam, 2020). Social work practice in the rehabilitation centers for juvenile delinquents had played a vital role in the reformation and transformation of the lives of delinquent children. In recent decades social work had been involved in rehabilitating juveniles in correctional facilities and their functions became a vital role in the criminal justice process in resolving cases of children engaging in criminality in international and local practice. The position of social workers became marginalized as law enforcement officials dominated the area of corrections (University of Missouri-Columbia, 2012). However, their job in prisons is still a necessity (Emmanuel \& Ponnuswami, 2019) and has a vital role in the Criminal Justice System (Sinha, 2020). In social work, the earliest practices involved substantial participation in prisons, in courts (Young \& Lomonaco, 2001), and deal with adult prisoners and youthful offenders (Bazemore, \& Walgrave, 1999; Shaikh, 2019).

Until today social work practice in youth rehabilitation centers has seldomly been studied, no results have shown about the experiences of social workers in dealing with the cases of child-in-conflict with the law (CICL), how to properly manage the rehabilitation process, and to address the challenges in rehabilitating CICL.

This research examines the perspectives of social workers engaged in the rehabilitation of CICL. It delves into the positive and negative experiences of social workers in handling CICL cases and rehabilitation using a qualitative approach in the Zamboanga Peninsula, Philippines. The next aim would explore the challeng- es the social workers faced during the initial contact with the CICL and the rehabilitation process. This study focused on the institutional-based of rehabilitating the CICL. Lastly, this study presents the coping strategies and mechanism of social workers about the stress and challenges they have faced in working with the cases of CICLs' rehabilitation process.

In the background of the rapidly evolving social work career and practice in the Philippines, particular attention is given to the recent trends on the experiences, challenges, and coping mechanisms involved in the practice of social work in rehabilitation centers for the juvenile.

Role of Social Workers in Juvenile Justice System

Social workers play a meaningful task in reforming and implementing intervention programs to the prisoners by catering the legal services, maintain family relationships, and after-care rehabilitation. In Yesudhas (2011) the role of social work was viewed as the provides help and support that is lacking in the prison programs or not attended properly.

As the vanguards in counseling with the child at risk and young offenders, social workers intermingle with these susceptible groups (Lim, 2017). Sinha (2020) cites the duty of social workers in rehabilitating juvenile delinquents and youth at risk, to avoid auxiliary loss of rights, to make society more inclusive, and to create amplified social stability. Such youth entrusted to social workers' care whose part is to guide by giving advice and intervention concentrated at plummeting the stress of adult life present among youth like family and teachers (Lim, 2017). Its highpoints the distinctive nature of working with youth, subsequently involving face-to-face human interaction, and encompassing and seeking to recognize the personal circumstances. It embraces working with adolescents who have fewer rights than adults, who are frequently 
susceptible, lack control, and maybe provocative - thereby creating room for exploitation or harm or manipulation. However, young people act in a distinct group with behavioral problems, their deeds regulated by social work as unabridged. It infers that social workers must construe the youth's real individualities so that they can assimilate it in the personal condition into the broader societal milieu.

Social workers have also proceeded as crucial probation officers, in the early days of the juvenile justice program, to rehabilitate young offenders. Rehabilitation was limited to turning lawbreakers into law-abiding people. For several years, corrections conceptualization has encompassed safe correctional facilities, such as infirmaries and jails, providing rehabilitation, education, treatment, and de-addiction services (Sinha, 2020).

The delivery of programs, counting pre-sentence investigation and monitoring, remediation, and returns to these communities, come to be their essential task (Shaikh, 2019). The juvenile programs aimed at rehabilitating young offenders in re-entry in mainstream society and stopping at-risk young people from dropping out of crime, thereby encouraging Social Workers to monitor their clients carefully (Lim, 2017), since they are spirited participants in concerted campaigns to foster the growth of young people (Walker, 2003). Therefore, it is precarious to find suitable rehabilitation programs for youth (Snyder \& Merritt, 2014), and within rehabilitation centers, social workers also face inimitable legal glitches and defiance quandaries.

\section{Challenges and Experiences of Social Workers}

As mentioned, the cornerstone and element of social work, knowing the client's nature is effective care personalization (Lyon, 2010). It can be a laborintensive and time-consuming task for social workers to create a connection with clients and to fathom their situation with a focus on the individual subjects (Parton, 2008). Notwithstanding, numerous researches pointed out that social workers face high levels of work-related stress due to limited resources, unclear job expectations, and communication with the organization (J. F. Boyas et al., 2015), secondary traumatic stress (Bride, 2007; Naturale, 2007) and burnout (Adams et al., 2006; J. Boyas \& Wind, 2010; Sprang et al., 2011). These contributed to child welfare is a demanding and challenging career.

Social workers perform important tasks, supporting vulnerable communities and ensuring their welfare. Because of frequent interactions with clients with trauma often these workers are vulnerable to experiencing burnout, secondary trauma, and vicarious trauma (Singer et al., 2020).

Adult/elder protective service and child protective service social workers receive low salaries, though they are burdened with high caseloads (Child Welfare Information Gateway, 2016; Otto \& Bell, 2003).

Social workers are among the few practitioners who have the most excellent experience and adequate training to recognize risk and protective factors (Torres \& Mariscal, 2016). However, in social work literature, the concept of joy is frequently lacking (Pooler et al., 2014).

In the Philippine setting, rehabilitation centers for youthful offenders are under the supervision of social workers. Hence the social workers involved in youth rehabilitation are exposed to challenging and enormous tasks. Relatively studies on social workers' experience in juvenile rehabilitation centers in the Philippines is not present in the literature. In the present study, the effort is to explore social workers' experiences handling minors' cases within youth rehabilitation centers in Western Mindanao, Philippines. 


\section{RESEARCH METHODS}

A qualitative-descriptive phenomenological design was used in this study to explore and describe the experiences of social workers in handling juvenile cases in the Philippines. This design is the most appropriate for the present study since it explores the shared experiences of social workers handling juvenile cases as it goes around the structures of consciousness in human experiences which the researcher believed is the most suitable for the exploratory study. It is in this context that the purpose of the phenomenological approach agrees with the idea of Lester (1999) to illuminate the specific and to identify phenomena through the perspective of the research key informants. All the key informants in this study discussed such a private event, most were eager to be part of the social and educational research, and all their stories to be made public (while having the assurance of a confidential identity) for in-depth research in the conduct of the study. Finally, key informants in this study described their experiences in handling juvenile cases.

This phenomenological qualitative study was conducted in the Philippines. Social workers from center-based and community-based assigned to handle cases of the juvenile are the key informants. There were 6 key informants in the focus group discussion (FGD) and 4 key informants in an in-depth interview (IDI). Purposive sampling was utilized in selecting the participants for this study. The main criterion for selecting the participants was the phenomenon of social workers handling juvenile cases. I made use of an interview guide containing open-ended questions. The interview guide was selfmade but undergo thorough validation. It particularly reflects the major points of the sub-problems. The research instrument consists of three parts: first part focused on the experiences of the informants in handling juvenile cases; the se- cond part dealt with the challenges encountered by the informants in handling juvenile cases, and the last part concerned the informant's coping mechanism on the challenges encountered in handling juvenile cases.

In conducting this study, I asked permission and approval from the Department of Social Welfare and Development (DSWD) regional office. The office explained to me the terms and conditions to be agreed upon and to be complied with by the researcher who intended research involving the agency, centers, and institution. As permission was granted, I strictly followed the terms and conditions stipulated in the contract. Before I conducted the interview and focus group discussion, I explained to the informants the purpose of the study in the manner in which the interview was done. I informed the informants that it will be recorded with the aid of a voice recorder to document the interview and with the undertaking not to divulge their identities. When the informants agreed to participate in the interview, I requested them to sign the Informed Consent Form to signify their willingness to proceed with the interview. The informed consent form in detail included the type of research intervention, voluntary participation, the purpose of the study and how it will be conducted; the benefits for the participants; how the privacy, anonymity, and confidentiality of the participants will be ensured, among others. Before the interview, I assured that the data gathered would be treated with the utmost confidentiality. To keep the anonymity, their place of origin, their names, and their offices are not mentioned. The names of the participants were substituted by pseudonyms.

As to the issue of the rigors of qualitative research is essential to the study, I strictly adhere to the standards in doing this qualitative research. I did consider quality criteria for ensuring that the study is trustworthy. I followed the criteria in- 
troduced by Lincoln \& Guba (2011) to include (a) credibility, (b) dependability, (c) generalizability, and (d) confirmability. To prevent that I could influence the result of the study, I observed the process of bracketing. To this effect, I made use of notes to fine-tune my data formulation and analysis. In the data gathering and data analysis, the ambiguous data in the transcript were referred to the informants for clarification. Further, for the verification of the theme developed during the data analysis, it was presented and reviewed, emergent themes were identified and accepted by the informants. Additionally, I consulted the ethics committee for the transcription, data analysis, findings, and interpretation. The discussion and exchange of thought with the committee was done in achieving dependability as part of the exploratory evaluation on the veracity of the results of this study. The shared informants' experiences were dealt with thoroughly and given enough depiction based on the informant's point of view of the experiences.

\section{RESULTS AND DISCUSSION}

There were 520 significant statements extracted from the informants' transcripts referring directly to the re- search phenomena. Formulated meanings were constructed from the significant statements and which were arranged into fourteen cluster themes which resulted in to form of three emergent themes. The emergent and sub-emergent themes were presented in table 1.

Positive Experiences of Informants in Handling Juvenile Cases

Social workers as the case managers for the juvenile in the court have been exposed to varied activities involving children in conflict with the law. The social role of the workers is responding to social calls to action for changing the lives and transforming every child into a productive and responsible person. Working with this juvenile who has been a victim of circumstances that lead them to violate certain laws is a fertile source of information to be cultivated to produce viable information on their experiences.

Marked by Reciprocity: Change is Possible Through Teaching Acceptance of Mistakes

This theme is associated with the transformation of a child's attitude while under the care, guidance, and supervision of a social worker. Reciprocity in psychology represents a reaction to the positive

Table 1. Emergent Themes and Subthemes

Source: Processed by the Author (2020)

\section{Emergent Theme}

\section{Cluster Themes/ Subthemes}

\section{Positive Experiences}

\section{- Marked by Reciprocity: Change is Possible Through \\ Teaching Acceptance of Mistakes}

- Selflessness: The Greatest Work of Life

\section{Negative Experiences \\ III. Challenges Encountered by the Informants}

- Every Action Has a Reaction

- Undoing: Burden in Action.

- The Complexity of Work: Duty Set no Boundaries,

- Test of Authority: Child Towards Rehabilitation.

IV. Coping Mechanism on - Adjustment: The Master of All Trade the Challenges
- Advocacy: Driver to Collaborate and Partnership 
action that was given. Children in Conflict with the Law (CICL) who are in rehabilitation centers have responded more cooperatively to the rehabilitation process and become kinder in dealing with the social workers who showed genuine concern to them while being antagonistic if dealt with differently.

In connection with the objective of my inquiry, I asked the informants about their personal experiences in handling juvenile cases specifically on the positive one. The majority of the participants experienced diverse transformations. To dig deeper into their responses, the informants stated that they see the transformation of behavior not only on the child but also in themselves while handling juvenile cases. Informant 7 in the focus group discussion confirmed that the transformation had come to light when you constantly teach and guide the juvenile on the right path. He narrated, but the outcome is, if there is a positive result at least, of course, I can answer your question. It somehow made me think that they can obey me which also serves as my stepping stone to improve myself and overcome my shortcomings. Actually, I can really say that there are still so many deficiencies. These challenges at work will be your stepping stone so that little by little, you will improve, and then you will achieve positive results. This means that it's a challenge on my part that the things that I taught to them will have a good result, will have an impact, that they will become obedient and well-behaved children, and that they will show a positive response to what I taught to them.

\section{Selflessness: The Greatest Work of Life}

Providing services to the juvenile and CICL for their best interest does not only limit within the time that is allocated for duty. Selflessness means setting aside personal needs and interests by showing greater concerns about the child's welfare while under the supervision and custody of the social worker. Further, this theme represents the considerable efforts exerted by the social workers to help the child who is under social and moral recovery to be treated regularly with unfailing love and dealt with in a manner appropriate to his or her well-being. In handling juvenile cases, social workers did not only engaged themselves to facilitate and assist in the proceedings of the case but they were also responsible for the welfare of the juvenile in the rehabilitation process. Helping juvenile in the rehabilitation and case proceedings requires attention, thus as a result, social workers spent most of their time working for the benefit of the juvenile even leaving their families and working beyond official time.

Informants opined that the indulgence to perform their work diligently, tediously, and being selfless in serving the juvenile has a positive outcome not only for the children but for their family as well. Informant 7 also narrated his experiences in working with juvenile cases in RRCY, he stated, this will be my last statement, sir, that when you work at RRCY, for me, it is really good. Why? Because if you already have your own family, this can help you and give you ideas on how to manage your own family in such a way that they will follow the right path. There are more insights that you will get here compared to the insights of our parents, which are very inadequate. Accordingly, there are many insights that we can apply to our own family especially in raising our children. That is why I don't have regrets about why I chose to work here. Although in my first years of working here, maybe for the first four years, I wanted to give up but I have no regrets that I have worked here because I gained so many insights and knowledge. As I have said a while ago, I was reformed here, it's as if I have gone through a rehabilitation process. I was also able to apply what I have learned here to my own family and the impact was really good. 
Negative Experiences of Informants in Handling Juvenile Cases

On the negative experience of social workers in handling juvenile cases, the following themes were created: Every Action Has a Reaction and Undoing and Burden in Action.

From the social workers' perspective, the negative experiences they faced are not merely caused by lack of resources which is a prevalent factor. It was rooted deeply in the counterparts of the workers who also take charges in handling the juvenile case, which become the source of abuses. The attitude and stressful aggressive behavior of juvenile delinquents toward social workers and reformation have greatly contributed to these negative experiences. Adding on the unpleasant experience is the perennial problem that was grounded in the parental practices and concerns toward the juvenile which greatly contribute to the current state of the child.

\section{Every Action Has a Reaction}

This theme refers to the experiences of social workers that are sources of stress circumstances in meeting the demand of their work and the needs of their clientele. Though the social workers strive to prevent themselves from being stressed in their work by not involving their feelings, the nature and line of their work as social workers causes stress. This theme explains how social workers became affected by the actions, moves, and the decision of the people involved in handling CICL from the moment that the juvenile is under their supervision. Besides, the demands, conditions, or situations of social workers and client relationships have significantly affected the balance of emotion and work.

Informant 3 elaborated how she was affected in handling juvenile, the unsatisfying experience that I had especially when handling children in conflict with the law is ahmm... There are some, espe- cially, when the child reach the police station without the presence of the social workers, while the police are preparing for the documents. The police will declare that the child is of legal age because there are no available supporting documents to confirm that the child is still minor. That is why, sometimes, the case will no longer reach WCPD, instead, it will go directly to the investigator and at the time that the juvenile is in the custody, the child will complain that there is physical violence involved. Although it was already being denied, again and again, I could say that because the child would really tell me, and we can also see that there are traces of physical abuse visible in the child's skin. That is my sad experience in handling children.

\section{Undoing: Burden in Action}

This denotes that when the counterparts of social workers during the initial contact with the child will not perform their task, in some situation, the child experiences an antagonistic approach from those who process them in the initial contact and pass on to the next stage, such as forwarding the child to the custody of social worker, without thoroughly accomplishing their function. The result will be detrimental to the child's welfare and is a burden on the part of the workers. As a result, the juvenile himself/herself will become not receptive to the process and displays aggressiveness. Though the social workers strive to avoid stress in their work by not involving their feelings but the nature and line of their cause stress.

Informant 2 described her hardship when the agencies involved did not perform their functions. She said there are some cases that are quite different or somewhat complicated. There are some situations wherein they might really get angry at me or they might have a different perception on several things. That is why, even though supposedly, we should work as partners, I will just work on my own 
and they will also work on their own. It actually created a division or a gap. Like in a situation where we were no longer informed about a particular case and it was already forwarded to us because a court order for custody has already been issued. Supposed to be, social workers must be informed first because we are the ones who will assist the juvenile in the shelter. There were really several situations that we were no longer informed. At some point, maybe, it's just fine that they will no longer inform us. But when the juvenile is already in the shelter, we need to make the case study. Why do we need to be informed? Because the task of the police here is only until the juvenile has been turned over. After the turnover, it is now our task to process and to do the rest of the works while the juvenile is still in the shelter which includes enhancement activities, and the task of helping and encouraging the parents to get involved in the formation activities. That is why those who are in-charge in the shelter really want us to be informed ahead. But since there is already a gap between the two. The police usually get angry at us, because somehow, we really need to be there to assist. It's just that the environment is no longer healthy between the two agencies.

Challenges of the Informants in Handling Juvenile Cases

This theme represents the obstacles that social workers have faced in working with different and diverse challenges in working and handling juvenile cases or the CICL.

\section{The Complexity of Work: Duty Set no Boundaries}

This implies that being a social worker working with juveniles, everything is possible to happen beyond the call of duty. Working with these youths requires no specific job description to be performed, no set time for work because anytime is work time for the caseworkers. There were times that the language and other aspects become the barrier in handling juvenile cases. Thus this represents a challenging task for them since workers will not only rely on the written methods of handling the child but will depend on the current situation.

Our informant said, yes of course. Because being a social worker, we don't own our time. Our attention might be called anytime and we have to sacrifice especially if you are available, so why not. By doing so, there are some personal businesses that you need to set aside for the sake of your call of duty. Especially, I don't have another source of income, this work is my bread and butter. So if you will say if my work did affect my personal life, my answer is yes. Even if I am at home, I still think about my work, how I might be able to finish it. Especially in my case wherein, recently, I have just undergone an operation, so I have not been in the office for a long time. So when I came back, I had to double my time to cope with all the works that I have to accomplish.

\section{Test of Authority: Children in the Direction} of Rehabilitation

Child compliance in the process of rehabilitation will challenge the social worker's ability to manipulate the situation. A juvenile before submitting himself/herself to the authority in the custody and rehabilitation will perceive it as a punishment. They perceived the situation, not the purpose of the social worker's undertakings toward his or her case. Rehabilitation centers where social workers worked out the improvement of the juvenile's cases by establishing rapport with their clientele, is a new environment for the juvenile which is very different from the outside world. Due to this, during the first stage in juvenile custody youth will display aggressive or non-participating behavior. We cannot deny that this situa- 
tion is present because the juvenile is still undergoing adjustment and adaptation.

Informant 6 in focus group discussion shared his challenging experience in terms of the juveniles' reaction towards him. He shared, it is here in this rehabilitation center, there are other CICLwherein they test the authority there. Their respect seemed to depend on who is in the authority.

\section{Coping Mechanism on the Challenges}

The social workers shared and exposed what are the coping mechanisms they applied and utilized to cope with the challenges they faced in handling juvenile cases.

\section{Adjustment: The Master of All Trade}

The manner how the social workers coped with the challenges they faced in handling juvenile cases would contribute to the existing body of knowledge in connection to the strategies in dealing with work-related stress and problems they faced. This theme elaborates the strategies on how social workers who are tasked with handling the juvenile case and rehabilitation process overcome and solve the challenges and problems they met.

Informant 1 unlocked her experiences on how she solves and cope with her challenges in handling juvenile case and rehabilitation, as she shared, to be relieved from stress, sometimes, I would file a leave of absence to give time for myself. There is also the time that you would experience a headache because of your work, I can really say that it is very stressful. Sometimes, I would go on a vacation, and sometimes, I would file a sick leave so that I could also relax.

\section{Advocacy: Driver to Collaborate and Part- nership}

Social workers have coped with the challenges they are facing through advocacy. Workers have perceived that their work has been given to them because of purpose by the Divine Creator. Other workers believe that juvenile delinquents are victims of circumstances who need the services and help of a social worker who receives them with widely opened arms. In the manner that social workers perform their work, they did not think of it as work but as advocacy. This leads them to collaborate and share their experiences with other social workers on the methods they applied in handling juvenile cases. This theme emerges based on how social workers have coped with the challenges and problems they faced in handling and working with a juvenile.

Informant 7 in focus group discussion also shared how the mentoring has helped him to overcome his challenges, then next sir, how I resolved it is through mentoring I received from other center staff. My senior staff, like mam meme, our center heads before, our co-workers before who are older than us. Just like that, I just listen to their advice because I know that I am still a neophyte in terms of working with CICL.

\section{CONCLUSION}

This study provides us with a glimpse of the experiences of social workers handling juvenile cases. The finding of the study revealed that social workers have faced experiences that poses a negative and positive impact on the lives of juveniles and those who work with their cases. Along with this, the social workers have experienced aggression from their clients and conflict among juveniles as part of the adjustment period of the child in the rehabilitation centers. The greatest achievement that a social worker is always longing for, the transformation of the life of the child under their management. This transformation can only be attained through proper nurturing and caring for the CICL. Further, during the initial contact with the CICL, if the process is not properly observed it will affect the proper 
disposition of cases in favor of the best interest of the child.

This study has also shown that in handling juvenile cases, social workers' attitudes and mindsets have effects in meeting their challenges towards working with the cases of a juvenile.

This study has shown that cultural background and communication and language barriers have a significant influence on the attitude of the child towards rehabilitation and case processing. Though social workers were trained to handle this occurrence in handling cases of juvenile but will lead to misunderstanding and confusion.

Another significant finding which made this study unique, revealed that the implementation of the law for the protection of children is widely recognized and implemented, however, officers who handled CICL have committed lapses in their responsibilities during the initial contact with the child.

Based on the findings and the conclusion drawn from this study, the following recommendations were made. First, DSWD must work in knowing the plight of social workers. This is an important aspect to understand the needs of every worker in working with the community and in the rehabilitation center to address his or her needs and the essentials for the case management which eventually will lead to effective work performance. In most cases, the social workers working with juvenile delinquents have encountered departmental and inter-agency difficulties. Second, inter-agency in the government involved in handling juvenile cases such as CICL evaluate their services offered to other agencies and juvenile delinquents. Since there exists a misunderstanding on the do's and don'ts of offering services in the process of handling juvenile cases.

Additionally, a study should be conducted to bridge the communication gap between center-based and community- based workers, social workers, and law enforcers to identify the boundaries in performing their respective functions.

Finally, on center-based and community-based approaches in handling juvenile cases, the current study has not identified the different experiences as to where they are based. Social workers in the community are facing challenges in the handling process during the initial contact with the child and with the agencies involved. On the other hand, the center-based workers have to deal not with the steps and inter-agency issues but with the issues of how to deal with the juveniles' rehabilitation. It is also encouraged that future research would focus on the relationship between community-based and center-based social workers and how the two work in handling juvenile delinquent cases.

\section{ACKNOWLEDGEMENT}

This study received a financial grant from J.H. Cerilles State College with BOT Resolution No. 019 series 2018. We deeply extend our thanks to Dr. Edgardo $\mathrm{H}$. Rosales, for facilitating the financial grant for this research. Additionally, the Department of Social Works and Development (DSWD) Region 9 for granting permission to conduct the study. Lastly, a deep appreciation to Mrs. Salome E. Mangubat, Center Head of Residential Based Facility for children in conflict with the law in Polanco Zamboanga del Sur for the support and assistance during the data gathering. This study was approved by the University of Cebu, Cebu City research censor.

\section{REFERENCES}

Adams, R. E., Figley, C. R., \& Boscarino, J. A. (2006). Compassion Fatigue and Psychological Distress in social workers. American Journal of Orthopsychiatry, 76(1), pp. 103108). 
Bazemore, S. G., \& Walgrave, L. (1999). Restorative Juvenile Justice: Repairing the Harm of Youth Crime. Monsey, NY: Criminal Justice Press, 3, 45-74. https://doi.org/10.5860/ choice.41-2927.14.

Boyas, J. F., Wind, L. H., \& Ruiz, E. (2015). Exploring patterns of employee psychosocial outcomes among child welfare workers. Children and Youth Services Review, 52, 174-183. https://doi.org/10.1016/ j.childyouth.2014.11.002

Boyas, J., \& Wind, L. H. (2010). Employment-based social capital, job stress, and employee burnout: A public child welfare employee structural model. Children and Youth Services Review, 32(3), 380$388 . \quad$ https://doi.org/10.1016/ j.childyouth.2009.10.009

Bride, B. E. (2007). Prevalence of secondary traumatic stress among social workers. Social Work, 52(1), 63-70. https://doi.org/10.1093/ sw/52.1.63

Emmanuel, B., \& Ponnuswami, I. (2019). The Status and Scope of Professional Social Work in Indian Correctional Setting. International Journal of Criminal Justice Sciences, 14(1), 3955. https://doi.org/110.5281/ zenodo.3243175

Kam, P. K. (2020). 'Social work is not just a job': The qualities of social workers from the perspective of service users. Journal of Social Work, 20(6), 775-796. https:// doi.org/10.1177/14680173198481 09

Lester, S. (1999). An introduction to phenomenological research. Retrieved February, 18(2), 1-4. https://doi.org/10.1111/j.1467- 9450.1984.tb01000.x

Lim, S. S. (2017). Youth workers' use of Facebook for mediated pastoralism with juvenile delinquents and youths-at-risk. Children and Youth Services Review, 81, 139-147. https://doi.org/10.1016/ j.childyouth.2017.08.004

Lincoln, Y. S., \& Guba, E. G. (2011). Paradigmatic controversies, contradictions, and emerging confluences. The Sage Handbook of Qualitative Research, 4, 97-128. https://bit.ly/3537uuy

Lyon, D. (2010). Surveillance, Power and Everyday Life. Palgrave Macmillan, Emerging digital spaces in contemporary society, 107-120. https:// doi.org/10.1057/9780230299047_1 8

Naturale, A. (2007). Secondary traumatic stress in social workers responding to disasters: Reports from the field. Clinical Social Work Journal, 35(3), 173-181. https://doi.org/10.1007/ s10615-007-0089-1

Parton, N. (2008). Changes in the form of knowledge in social work: From the "social" to the "informational"? British Journal of Social Work, 38(2), 253-269. https://doi.org/10.1093/ bjsw/bcl337

Pooler, D. K., Wolfer, T., \& Freeman, M. (2014). Finding joy in social work II: Intrapersonal sources. Social Work (United States), 59(3), 213-221. https://doi.org/10.1093/sw/ swu020

Shaikh, R. (2019). Coming of Age of Criminal Justice Social Work in India. International Journal of Criminal Justice Sciences -, 14(1), 9-21. 
Otoritas : Jurnal Ilmu Pemerintahan, 11 (1), April 2021, 44

https://doi.org/110.5281/

zenodo.3242022

Singer, J., Cummings, C., Moody, S. A., \& Benuto, L. T. (2020). Reducing burnout, vicarious trauma, and secondary traumatic stress through investigating purpose in life in social workers. Journal of Social Work, 20 (5), 620-638. https:// doi.org/10.1177/14680173198530 57

Sinha, R. (2020). Contemporary challenges to social work education and practice in India. International Journal of Criminal Justice Sciences, 14(June 2018), 54-63. https:// doi.org/10.4324/9780429321818-6

Snyder, S. M., \& Merritt, D. H. (2014). Do childhood experiences of neglect affect delinquency among child welfare involved-youth? Children and Youth Services Review, 46, 6471. https://doi.org/10.1016/ j.childyouth.2014.08.007

Sprang, G., Craig, C., \& Clark, J. (2011). Secondary traumatic stress and burnout in child welfare workers: A comparative analysis of occupational distress across professional groups. Child Welfare, 90(6), 149-168. http:// europepmc.org/article/ MED/22533047

Torres, G. C., \& Mariscal, V. V. (2016). SOCIAL WORKERS PERSPECTIVES OF THE PROTECTIVE AND RISK FACTORS THAT AFFECT YOUTH IN THE JUVENILE JUSTICE SYSTEM
AND CHILD WELFARE SYSTEM. In Electronic Theses, Projects, and Dissertations. https:// scholarworks.lib.csusb.edu/ etd/324/?

utm_source=scholarworks.lib.csusb. edu $\% 2$ Fetd $\%$ 2F324\&utm_medium=PDF\&utm_ca mpaign=PDFCoverPages

University of Missouri-Columbia. (2012). Social workers should reclaim role in juvenile corrections system , researcher says. https://phys.org/ news/2012-02-social-workersreclaim-role-juvenile.html

Walker, J. A. (2003). The essential youth worker. In F. A. Villarruel, D. F. Perkins, L. M. Borden, \& J. G. Keith (Eds.), Community youth development: Programs, policies, and practices (pp. 373-393). Thousand Oaks, CA: Sage. Thousand Oaks, CA: Sage., 373-393.

Yesudhas, R. (2011). Social Work Intervention With Prisoners: the Case of Varhad in Maharashtra. Rajagiri Journal of Social Development, 3(June), 99-108. https://www.researchgate.net/ publication/233862396_SOCIAL_W ORK_INTERVENTION_WITH_PRISO NERS_THE_CASE_OF_VARHAD_IN_M AHARASHTRA

Young, D. S., \& Lomonaco, S. W. (2001). Incorporating content on offenders and corrections into social work curricula. Journal of Social Work Education, 37(3), 475-491. 